\title{
hERG1 is involved in the pathophysiological process and inhibited by berberine in SKOV3 cells
}

\author{
DUO ZHI $^{1 *}$, KUN ZHOU $^{2 *}$, DAHAI YU ${ }^{3}$, XIAOFAN FAN $^{1}$, \\ JUAN ZHANG ${ }^{1}$, XIANG LI $^{1}$ and MEI DONG ${ }^{1}$ \\ ${ }^{1}$ Department of Pharmacy, Harbin Medical University Cancer Hospital, Harbin, Heilongjiang 150040; \\ ${ }^{2}$ General Hospital of Heilongjiang Province Land Reclamation Bureau, Harbin, Heilongjiang 150088; \\ ${ }^{3}$ Department of Pharmacology, College of Pharmacy, Harbin Medical University, \\ Harbin, Heilongjiang 150081, P.R. China
}

Received April 13, 2018; Accepted March 25, 2019

DOI: $10.3892 / \mathrm{ol} .2019 .10263$

\begin{abstract}
The human ether-a-go-go-related potassium channel 1 (hERG1) is a functional component of the voltage-gated Kv11.1 potassium channel, which is commonly described as a crucial factor in the tumorigenesis of a variety of tumors. Ovarian cancer is one of the most severe types of cancer, with an extremely poor prognosis. Advances have been made in recent years; however, drug resistance and tumor recurrence remain critical issues underlying satisfactory treatment outcomes. Therefore, more effective antitumor agents with low levels of drug resistance for ovarian cancer treatment are urgently required in clinical practice. In the present study, hERG1 mRNA expression in ovarian tumor tissues and cell lines were measured by reverse transcription-quantitative polymerase chain reaction. Immunohistochemistry and western blotting were used to assess the expression levels of hERG1 protein. Cell proliferation, migration and invasion were assessed by Cell Counting Kit- 8 assay and Transwell assay. A tumor xenograft assay was used to determine the growth of tumors in vivo. It was demonstrated that the expression levels of hERG1 were significantly elevated in ovarian cancer tissues and expressed in ovarian cancer cell lines, particularly in SKOV3 cells. Abnormal hERG1 expression was significantly associated with the proliferation, migration and invasion abilities of ovarian cancer. In addition, berberine (BBR) may be used as a potential drug in the treatment of ovarian cancer, possibly due to its inhibitory effects on the hERG1 channels. In conclusion, the present study demonstrated that hERG1 may be
\end{abstract}

Correspondence to: Professor Mei Dong, Department of Pharmacy, Harbin Medical University Cancer Hospital, 6 Baojian Road, Harbin, Heilongjiang 150040, P.R. China

E-mail: dongmeiyds@sina.com

*Contributed equally

Key words: ovarian cancer, berberine, human ether-a-go-go-related potassium channel 1 , proliferation, invasion, migration a potential therapeutic target in the treatment of ovarian cancer and provided novel insights into the mechanism underlying the antitumor effects of BBR in ovarian cancer.

\section{Introduction}

Ovarian cancer is one of the most common types of gynecological malignancies worldwide with an extremely low survival rate of 5 years $(1,2)$. Patients diagnosed at the early stages of ovarian cancer respond to platinum-based combinatorial chemotherapies; however, relapse and drug resistance are prevalent, leading to treatment failure and poor prognosis (3). At present, due to the lack of reliable approaches for early diagnosis, ovarian cancer is generally diagnosed at an advanced stage when surgical resection or chemotherapy are generally ineffective (4). Therefore, molecular alterations in tumors, particularly those involved in cell proliferation, apoptosis and invasion signaling pathways, are being investigated for potential developments in early diagnosis and targeted therapy.

Potassium channels are the most widely distributed type of ion channel and are associated with numerous biological processes in almost all living organisms $(5,6)$. Potassium channels are commonly expressed in excitable cells and are often aberrantly expressed in neoplastic cell lines and primary types of human cancer $(7,8)$. This contributes to the regulation of several factors associated with neoplastic progression, including cell proliferation, apoptosis, invasion and metastasis (9-11). The inhibition of potassium channels has been demonstrated to exert antineoplastic activities in various types of tumors in vitro and in vivo $(12,13)$. This evidence suggests that potassium channels may be considered as possible targets for antineoplastic therapy.

Human ether a-go-go related potassium channels (hERGs) are voltage-dependent potassium channels that serve important roles in the terminal repolarization on human ventricular myocytes (14). A number of studies over the past two decades have demonstrated that plasma membrane hERG1 is often aberrantly expressed in various types of cancer and serves essential roles in numerous crucial cellular events, including electrophysiological activity and signaling conduction $(15,16)$. However, to the best of our knowledge, few investigations into the function of hERG1 in human ovarian cancer have been conducted $(17,18)$ 
and the underlying mechanisms regulating hERG1 expression in ovarian cancer progression remain unknown.

Previous studies have revealed that numerous traditional Chinese herbal medicines (19-21), including berberine (BBR), a clinically important natural isoquinoline alkaloid that was the subject of our previous study (22), exhibit significant antitumor activities and reverse the drug resistance of cancer cells. BBR has been reported to exert antitumor activity against various types of cancer, including gastric, oral, prostate and ovarian cancer (23-25). The molecular targets of BBR include protein kinase B, p53, mitogen-activated protein kinase, nuclear factor $-\kappa \mathrm{B}$ and signal transducer and activator of transcription 3 , which are pivotal factors in regulating cell growth, apoptosis, invasion and angiogenesis of cancer (26-28). However, since tumor progression is a complicated pathological process, other molecular targets may be involved in the antitumor effects exhibited by BBR. It is common that multi-target combination therapy for the treatment of tumors is administered as the main treatment approach to overcome drug resistance and improve the prognosis of patients with cancer (29). Therefore, investigations into the potential molecular mechanisms underlying the antitumor properties of BBR in ovarian cancer are necessary and valuable for the development of multi-targeted therapy.

The present study revealed that hERG1 was involved in the regulation of proliferation, migration and invasion of ovarian cancer cells. Treatment with BBR was observed to efficiently inhibit these biological activities in vivo and in vitro. The results of the present study provide novel insights into the molecular mechanism underlying the antitumor effects of BBR and may contribute to the development of novel therapeutic strategies for the treatment of ovarian cancer.

\section{Materials and methods}

Tissue samples. A total of 28 ovarian carcinoma tissue samples and matched adjacent non-tumorigenic tissues samples ( $2 \mathrm{~cm}$ from cancerous tissues) were obtained from patients who underwent surgical resection of the tumor at Harbin Medical University Cancer Hospital (Harbin, China) between May 2015 and March 2016. The average age of the patients was 48 years old. The samples were stored in liquid nitrogen until total RNA or protein were extracted. The present study was approved by the Ethical Committee of Harbin Medical University Cancer Hospital and written informed consent was obtained from all patients.

Immunohistochemical assay. All tissues were initially fixed in $10 \%$ formalin for $48 \mathrm{~h}$ at $4^{\circ} \mathrm{C}$ and embedded in paraffin. Section of $5 \mu \mathrm{m}$ thickness were pre-incubated with $5 \%$ goat serum (cat. no. C0265; Beyotime Institute of Biotechnology, Shanghai, China) as a blocking buffer for $2 \mathrm{~h}$ at room temperature, and then incubated with primary hERG1 antibody (1:200; cat. no. sc-377388; Santa Cruz Biotechnology, Inc., Dallas, TX, USA) overnight at $4^{\circ} \mathrm{C}$; After washing three times with PBS at room temperature, the sections were incubated with peroxidase-labeled anti-mouse antibody (1:50; cat. no. A0216; Beyotime Institute of Biotechnology) for $30 \mathrm{~min}$ at room temperature. The peroxidase activity was detected with diaminobenzidine (DAB; Beyotime Institute of Biotechnology). The stained sections were analyzed using a fluorescence Olympus
BX51 microscope (magnification, x200; Olympus Corporation, Tokyo, Japan). The immunohistochemical staining results were scored as the sum of intensity and percentage scores, according to the staining intensity $(0=$ negative; $1=$ weak/trace; $2=$ moderate; and $3=$ strong) and the percentage of positive cells $(0, \leq 10 ; 1,11-25 ; 2,26-50 ; 3,51-75$; and $4,76-100 \%)$. This grading produced a final score of $0-12$, and samples were separated into groups based on low (0-4) or high (6-12) scores.

Reagents. BBR and DMSO were purchased from Sigma-Aldrich; Merck KGaA (Darmstadt, Germany). BBR was dissolved in $10 \%$ DMSO and $90 \%$ deionized water. The drug solution was diluted to concentrations of 5, 10,30,50 and 100 $\mu \mathrm{M}$ in RPMI-1640 culture medium (Beyotime Institute of Biotechnology) prior to use at room temperature. For cellular experiments, cells were incubated with different concentrations of $\operatorname{BBR}(5,10,30,50$ or $100 \mu \mathrm{M}$ ) for 24,48 and $72 \mathrm{~h}$ at $37^{\circ} \mathrm{C}$, respectively. Cells in the blank control group were treated with $1 \%$ DMSO.

Cell culture and transfection. OVCAR-3, SKOV3, HO-8910, A2780 and ES-2 ovarian carcinoma cell lines were obtained from the Cancer Institute of Harbin Medical University. OVCAR-3 and SKOV3 cells were maintained in RPMI-1640 medium (Beyotime Institute of Biotechnology) supplemented with $12 \%$ (v/v) FBS (Thermo Fisher Scientific, Inc., Waltham, MA, USA). HO-8910, A2780 and ES-2 ovarian carcinoma cells were maintained in DMEM (Beyotime Institute of Biotechnology) supplemented with $12 \%$ (v/v) FBS (Thermo Fisher Scientific, Inc.). All cell lines were cultured at $37^{\circ} \mathrm{C}$ with $5 \% \mathrm{CO}_{2}$ in a humidified incubator.

Short hairpin (sh)RNA-hERG1 plasmid $(4 \mu \mathrm{g})$ and shRNA-control (scrambled short hairpin RNA sequence) plasmids (4 $\mu \mathrm{g})$ (Shanghai GeneChem Co., Ltd., Shanghai, China), were used to transfect SKOV3 cells. All transfections were performed using Lipofectamine ${ }^{\circledR} 2000$ (Invitrogen; Thermo Fisher Scientific, Inc.), according to the manufacturer's protocol. Cells were harvested at $24 \mathrm{~h}$ after transfection.

Cell proliferation assay. Cell proliferation was determined by Cell Counting kit-8 (CCK8) assay. Briefly, SKOV3 cells were seeded in 96 -well plates at $1 \times 10^{5}$ cells/well and maintained for $24 \mathrm{~h}$ at $37^{\circ} \mathrm{C}$ to allow cell adhesion. Subsequently, the cells in various groups $(5,10,30,50$ or $100 \mu \mathrm{M}$ berberine for 24 , 48 or $72 \mathrm{~h}$ ) were incubated with $10 \mu \mathrm{l}$ CCK8 for $2 \mathrm{~h}$ and the absorbance was measured at $450 \mathrm{~nm}$ using a microplate reader (Olympus Corporation). The proliferation of treated cells was assessed by comparison with the blank control group. Each experiment was performed in triplicate.

Total RNA extraction and reverse transcription-quantitative polymerase chain reaction ( $R T-q P C R)$. OVCAR-3, SKOV3, HO-8910, A2780 and ES-2 ovarian carcinoma cells and tissue specimens were homogenized in TRIzol reagent (Invitrogen; Thermo Fisher Scientific, Inc.) to isolate total RNA, according to the manufacturer's protocols. The concentration of RNA was detected with a NanoDrop spectrophotometer (NanoDrop Technologies; Thermo Fisher Scientific, Inc.). The total RNA of each sample $(1 \mu \mathrm{g})$ was reverse transcribed using random primers and a PrimeScript 1st Strand cDNA Synthesis kit (Takara Biotechnology Co., Ltd., Dalian, China), according to the 
manufacturer's protocols. qPCR was performed using a SYBR green fluorescent dye (PCR master mix; Applied Biosystems; Thermo Fisher Scientific, Inc.) with the following thermocycling conditions: Pre-denaturation at $95^{\circ} \mathrm{C}$ for $45 \mathrm{sec}$, followed by 40 cycles of denaturation at $95^{\circ} \mathrm{C}$ for $15 \mathrm{sec}$, and annealing and extension at $55^{\circ} \mathrm{C}$ for $30 \mathrm{sec}$. The relative hERG1 expression levels were calculated based on the $2^{-\Delta \Delta \mathrm{Cq}}$ method and normalized to GAPDH level in each sample (30). Each experiment was performed in triplicate. The primer sequences for qPCR were as follows: hERG1 forward, 5'-CAGCGGCTGTACTCGGGCACA G-3' and reverse, 5'-CAGAAGTGGTCGGAGAACTC-3'; and GAPDH forward, 5'-GTCAACGGATTTGGTCGTATTG-3' and reverse, 5'-AGTGATGGCATGGACTGTGG-3'.

Western blot analysis. Briefly, total protein was extracted from tissues or OVCAR-3, SKOV3,HO-8910, A2780 and ES-2 ovarian carcinoma cell lines with RIPA buffer (Beyotime Institute of Biotechnology) and the protein concentrations were determined using a bicinchoninic acid protein assay (Pierce; Thermo Fisher Scientific, Inc.). Subsequently, proteins (50 $\mu \mathrm{g} / \mathrm{lane})$ were separated by SDS-PAGE ( $8 \%$ gel) and transferred onto a nitrocellulose membrane (Bio-Rad Laboratories, Inc., Hercules, CA, USA). To prevent non-specific binding, the membrane was blocked with 5\% skimmed milk in PBS with Tween-20 (0.25\%) for $2 \mathrm{~h}$ at room temperature. Subsequently, the membrane was incubated with hERG1 antibody (1:1,000; cat. no. sc-377388; Santa Cruz Biotechnology, Inc.) or $\beta$-actin antibody (1:1,000; cat. no. ab8227; Abcam, Cambridge, UK) in PBS at $4^{\circ} \mathrm{C}$ overnight. Subsequently, the membrane was rinsed with PBST three times, which was followed by incubation with corresponding IRDye ${ }^{\circledR} 800 \mathrm{CW}$ fluorescent secondary antibodies (1:8,000; cat. nos. anti-rabbit 926-32211 and anti-mouse 926-32210; LI-COR Biosciences, Lincoln, NE, USA) for $1 \mathrm{~h}$ at room temperature. Finally, the protein bands were visualized using an Odyssey infrared imaging system (LI-COR Biosciences) at $800 \mathrm{~nm}$.

Transwell assays. SKOV3 cells in serum-free RPMI-1640 medium (200 $\mu \mathrm{l}$ containing $5 \times 10^{5}$ cells for BBR group, $200 \mu \mathrm{l}$ containing $2.5 \times 10^{5}$ cells for other groups) were added to the upper Transwell chambers (pore size, $8 \mu \mathrm{m}$; Corning Inc., Corning, NY, USA). The chambers were coated with Matrigel (BD Biosciences, Franklin Lakes, NJ, USA) for the invasion assays but not the migration assays. The bottom chamber was filled with $700 \mu 1$ RPMI-1640 medium containing 15\% FBS. The cells were cultured in an incubator at $37^{\circ} \mathrm{C}$ with $5 \% \mathrm{CO}_{2}$ for $24 \mathrm{~h}$, then the cells were fixed in $4 \%$ paraformaldehyde for 15 min. Subsequently, the cells were washed with PBS and stained with $0.1 \%$ crystal violet for $10 \mathrm{~min}$ at room temperature. For analysis, five fields were randomly selected and the number of stained cells was counted under a light microscope at magnification of x200 (Nikon Corporation, Tokyo, Japan). Data are expressed as the mean number of cells per insert.

In vivo tumor xenograft study. Five-week-old BALB/c-nu/nu nude mice were purchased from the Beijing Vital River Laboratory Animal Technology Co., Ltd. (Beijing, China). The experimental protocols were approved by the Ethics Committee of Harbin Medical University (Harbin, China). A total of 72 mice (36 females, 36 males) weighing 20-25 g each, were maintained under a $12-\mathrm{h}$ light/dark cycle at $20.0-26.1^{\circ} \mathrm{C}$ and $35-70 \%$ humidity.
Table I. Associations between hERG1 expression and clinicopathological features of patients with ovarian cancer.

\begin{tabular}{|c|c|c|c|}
\hline \multirow[b]{2}{*}{ Variables } & \multicolumn{2}{|c|}{$\begin{array}{c}\text { hERG1 } \\
\text { expression, } \mathrm{n}\end{array}$} & \multirow[b]{2}{*}{ P-value } \\
\hline & Low & High & \\
\hline Age, years & & & 0.6193 \\
\hline$\leq 50$ & 7 & 8 & \\
\hline$>50$ & 8 & 5 & \\
\hline Tumor diameter, cm & & & 0.8232 \\
\hline$<8$ & 3 & 8 & \\
\hline$\geq 8$ & 4 & 13 & \\
\hline Ascite & & & 0.7051 \\
\hline Negative & 6 & 7 & \\
\hline Positive & 9 & 6 & \\
\hline Lymph node metastasis & & & $0.0044^{\mathrm{a}}$ \\
\hline Negative & 9 & 5 & \\
\hline Positive & 1 & 13 & \\
\hline Distant metastasis & & & $0.0204^{b}$ \\
\hline Negative & 7 & 3 & \\
\hline Positive & 4 & 14 & \\
\hline Differentiation & & & 0.7483 \\
\hline Good & 3 & 4 & \\
\hline Moderate & 5 & 3 & \\
\hline Poor & 7 & 6 & \\
\hline Tumor location & & & 0.694 \\
\hline Bilateral & 8 & 10 & \\
\hline Unilateral & 6 & 4 & \\
\hline
\end{tabular}

Datawereanalyzedusing $\chi^{2}$ test.hERG1, humanether-a-go-go-related potassium channel $1 .{ }^{\mathrm{a}} \mathrm{P}<0.01,{ }^{\mathrm{b}} \mathrm{P}<0.05$.

Food and water were freely accessible to mice. SKOV3 cells ( $2 \times 10^{6}$ per mouse) were subcutaneously injected into the flank of each mouse. Following the outgrowth of palpable tumors, the mice were randomly divided into four groups ( $n=3$ for each group) and fed by oral gavage with saline or BBR (20 mg/kg), twice per week. BBR was dissolved in carboxymethylcellulose sodium for use via oral gavage. Tumors volumes were calculated using the following formula: Volume $=\mathrm{L} \times(\mathrm{W})^{2} / 2$, where $\mathrm{L}$ is the longest diameter and $\mathrm{W}$ is the shorter diameter. At the end of the present study, mice were euthanized and tumor tissues were harvested for further research.

Statistical analysis. Data are presented as the mean \pm standard error of the mean of triplicate experiments and were analyzed with SPSS version 13.0 software (SPSS, Inc., Chicago, IL, USA). The $\chi^{2}$ test was used to analyze the association of hERG1 expression with clinicopathologic features of ovarian cancer. Unpaired Student's t-test and one-way analysis of variance with a Student-Newman-Keuls post hoc test were used to determine the significance of differences between two groups and three or more groups, respectively. $\mathrm{P}<0.05$ was considered to indicate a statistically significant difference. 
A

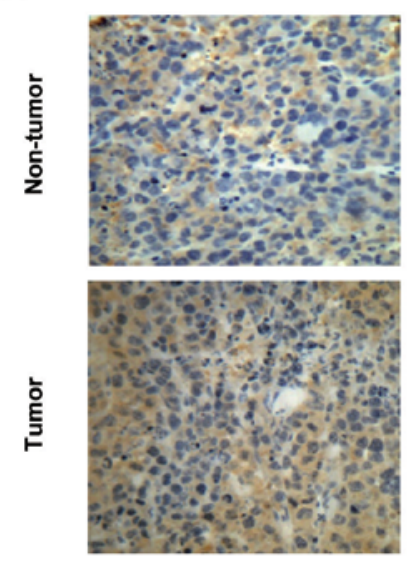

D

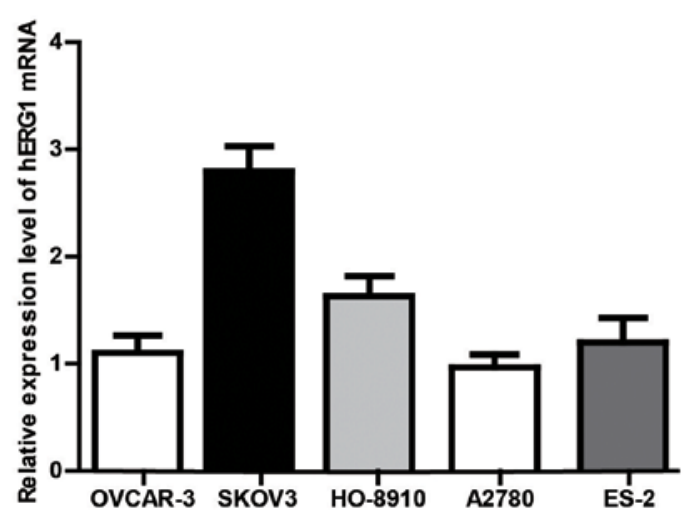

B

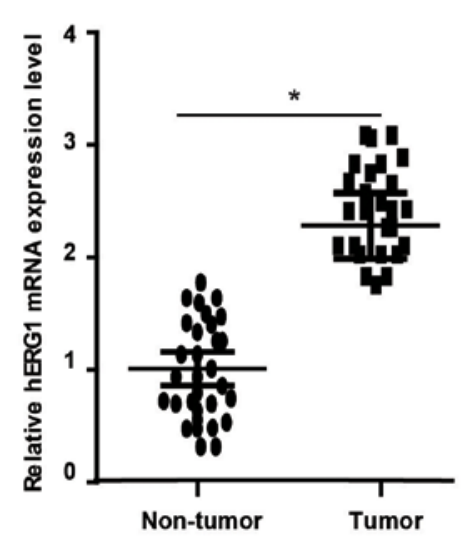

C

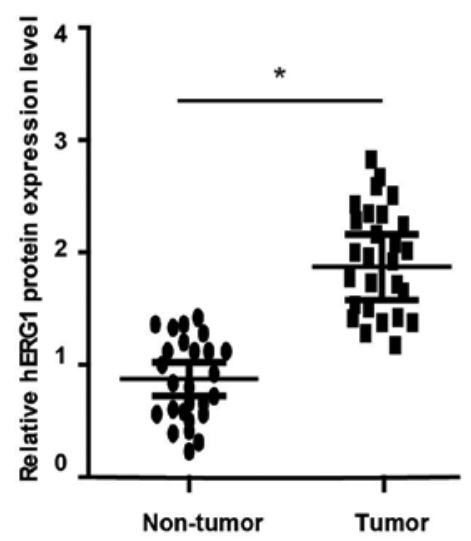

E

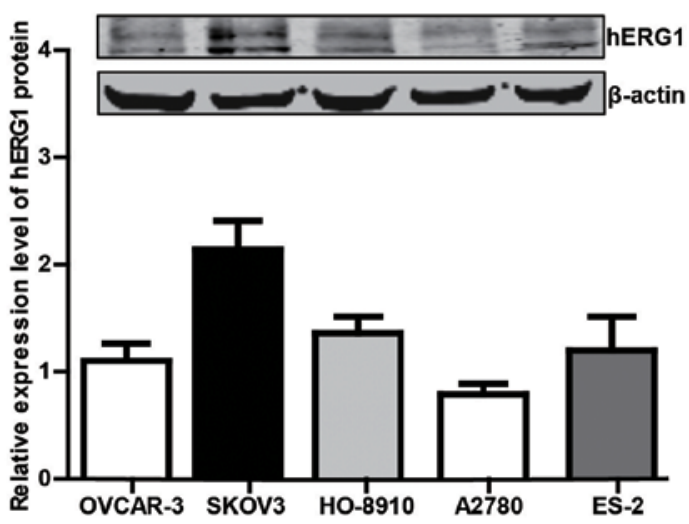

Figure 1. Expression patterns of hERG1 in ovarian cancer tissues and cell lines. (A) Expression levels of hERG1 analyzed by immunohistochemistry (magnification, $\mathrm{x} 400)$. (B) Reverse transcription-quantitative polymerase chain reaction and (C) western blot analysis of hERG1 expression in ovarian cancer and matched adjacent non-tumor tissues $(n=28)$. (D) Relative mRNA and (E) protein expression levels of hERG1 in various ovarian cancer cell lines ( $\mathrm{n}=3$ ). ${ }^{*} \mathrm{P}<0.05$. hERG1, human ether-a-go-go-related potassium channel 1.

\section{Results}

hERG1 is upregulated in human ovarian cancer. In order to determine the role of hERG1 in ovarian cancer development, the mRNA and protein expression levels of hERG1 were detected by RT-qPCR and western blotting. A total of 28 tumor tissues and matched non-tumor tissues were obtained from patients with ovarian cancer with a median age of 48 years in the present study. The association of hERG1 expression with clinicopathologic features of ovarian cancer is presented in Table I. These results demonstrate that hERG1 expression level is significantly associated with ovarian cancer distant metastasis and lymph node metastasis. The immunohistochemical assay results revealed that the protein expression levels of hERG1 were markedly higher in ovarian cancer tissues compared with non-tumor tissues (Fig. 1A). As presented in Fig. 1B and C, the mRNA and protein expression levels of hERG1 were significantly upregulated in tumor tissues compared with non-tumor tissues, as expected. Furthermore, the expression level of hERG1 in OVCAR-3, SKOV3, HO-8910, A2780 and ES-2 ovarian cancer cell lines was investigated. The results (Fig. 1D and E) revealed that hERG1 was generally expressed in these ovarian cancer cell lines and highly expressed in SKOV3, in particular. Therefore, in the present study, SKOV3 cells were used for further analysis.
BBR inhibits cell proliferation and hERG1 in SKOV3 cells. Subsequently, the effects of BBR on SKOV3 cells were investigated using a CCK8 assay. SKOV3 cells were treated for 24,48 and $72 \mathrm{~h}$ with BBR at concentrations ranging between 5 and $100 \mu \mathrm{M}$, and the results were compared with the control group treated with DMSO. The CCK8 assay results demonstrated that BBR inhibited the proliferation of SKOV3 cells in a time- and dose-dependent manner (Fig. 2A). The proliferation of cells treated for $48 \mathrm{~h}$ decreased more significantly compared with cells treated for $24 \mathrm{~h}(\mathrm{P}<0.05)$; however, no difference was observed between cells in the 48 and $72 \mathrm{~h}$ groups. Simultaneously, BBR significantly reduced the mRNA and protein expression levels of hERG1 in a dose-dependent manner (Fig. 2B-D), which suggests that hERG1 may serve a role in the proliferation of SKOV3 cells. Expression levels of hERG1 decreased significantly in response to $10 \mu \mathrm{M}$ BBR and the $\mathrm{IC}_{50}$ of BBR was $9.8 \mu \mathrm{M}$ at $48 \mathrm{~h}$. Therefore, in subsequent experiments BBR was administered to SKOV3 cells for $48 \mathrm{~h}$ at a concentration of $10 \mu \mathrm{M}$.

Knockdown of hERG1 in SKOV3 cells. To investigate the effects of hERG1 on tumor biological activities, expression levels of hERG1 in SKOV3 cells were downregulated using a shRNA-hERG1 plasmid. As presented in Fig. 3, the mRNA and protein expression levels of hERG1 in SKOV3 cells transfected 
A

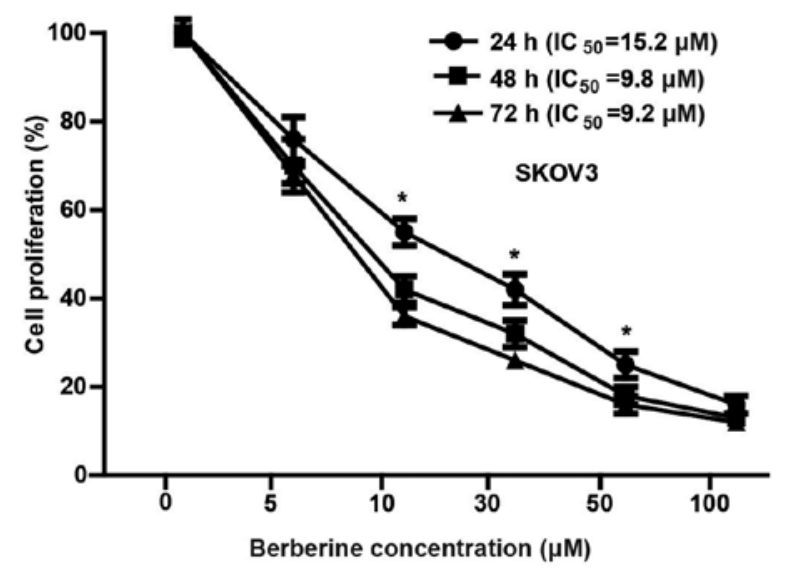

C

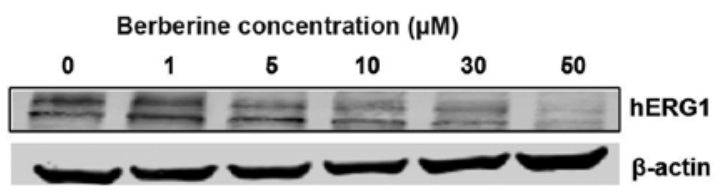

B

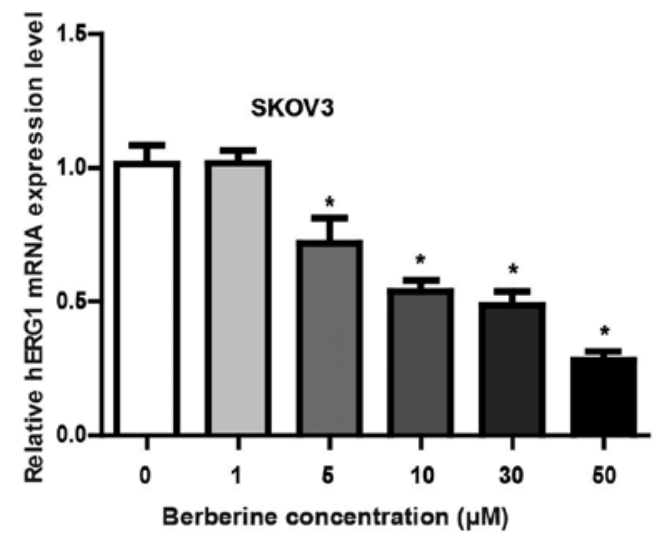

D

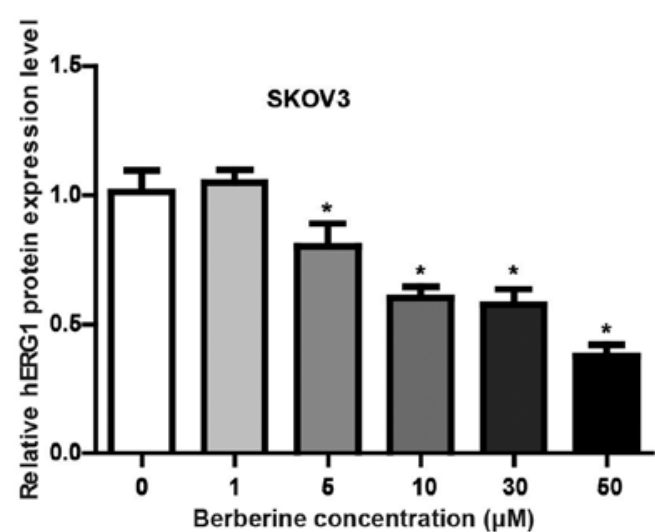

Figure 2. BBR inhibits cell proliferation and hERGlexpression in SKOV3 cells. (A) BBR (10, 30, 50 and $100 \mu \mathrm{M})$ inhibited the growth of SKOV3 cells in a time- and dose-dependent manner. Proliferation of cells treated with indicated doses of BBR for 24,48 and $72 \mathrm{~h}$ was assessed using a Cell Counting kit- 8 assay. "P<0.05 vs. $0 \mu \mathrm{M}$. (B) BBR inhibited the expression of hERG1 mRNA in a dose-dependent manner at $48 \mathrm{~h} .{ }^{*} \mathrm{P}<0.05$ vs. $0 \mu \mathrm{M}$. (C) BBR inhibited the expression of hERG1 protein in a dose-dependent manner at $48 \mathrm{~h}$. (D) Quantification of hERG1 protein expression levels. ( $\mathrm{n}=3$ ). ${ }^{*} \mathrm{P}<0.05 \mathrm{vs} .0 \mu \mathrm{M}$. BBR, berberine; hERG1, human ether-a-go-go-related potassium channel 1.

A

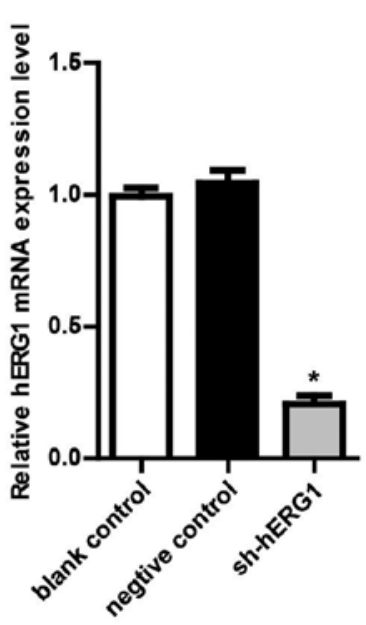

B

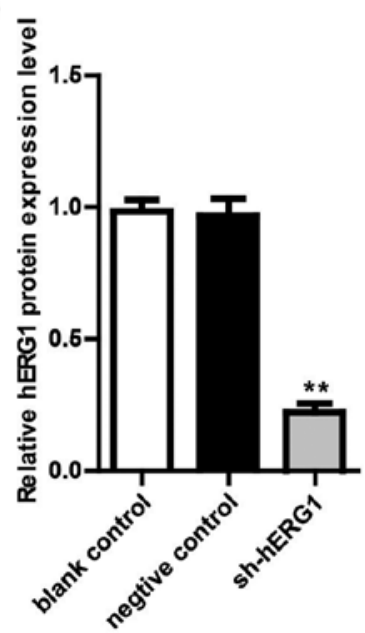

SKov3

blank control negtive control sh-hERG1

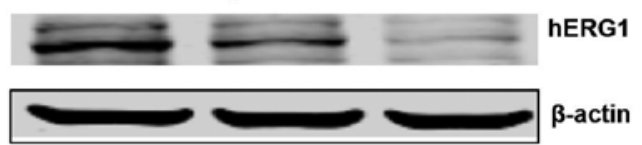

Figure 3. Knockdown of hERG1 in SKOV3 cells. (A) Knockdown of hERG1 by transfection with sh-hERG plasmid significantly reduced the mRNA expression levels of hERG1 in SKOV3 cells compared with the control group. (B) Knockdown of hERG1 gene by sh-hERG plasmid significantly reduced the protein expression of hERG1 compared with the control group in SKOV3 cells $(\mathrm{n}=3) .{ }^{*} \mathrm{P}<0.05,{ }^{* *} \mathrm{P}<0.01$ vs. blank control. hERG1, human ether-a-go-go-related potassium channel 1; sh, short hairpin RNA.

with the shRNA-hERG1 plasmid were significantly decreased compared with in the control groups.
hERG1 is involved in the pathophysiological process of SKOV3 cells. The effects of hERG1 on the proliferation 
A

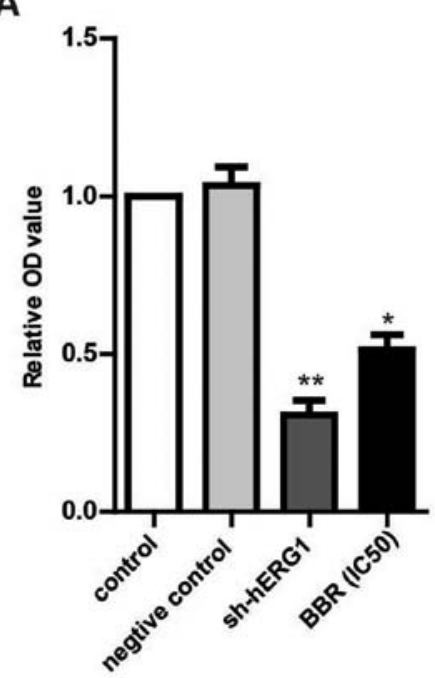

B

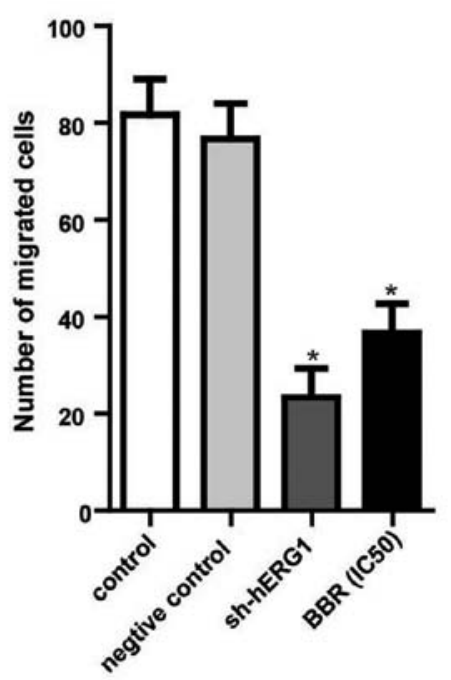

C

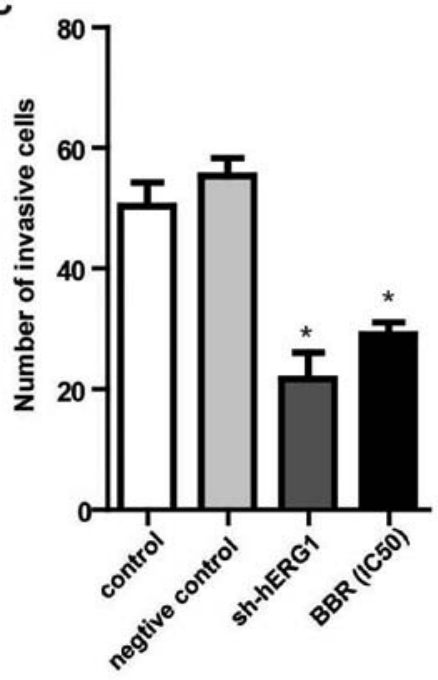

D

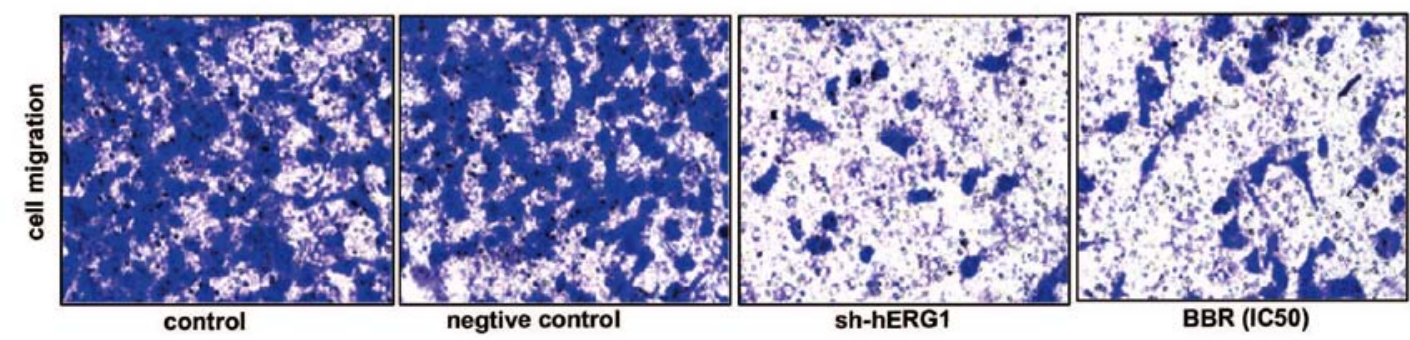

E

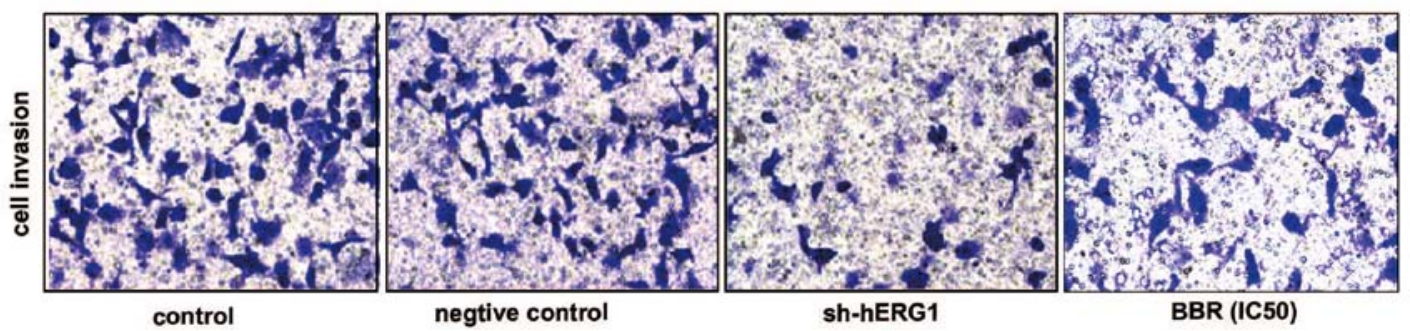

Figure 4. hERG1 is involved in the pathophysiological processes of SKOV3 cells. (A) Knockdown of hERG1 significantly reduced the cell proliferation activity in SKOV3 cells compared with in control cells. BBR at a concentration of $10 \mu \mathrm{M}$ was used as a positive control. Quantification of the (B) migration and (C) invasion abilities of SKOV3 cells in different treatment groups. Images (magnification, x200) represent the (D) migrating cells and (E) invading cells in the Transwell and Matrigel invasion assays, respectively. $\mathrm{n}=3 .{ }^{*} \mathrm{P}<0.05,{ }^{* *} \mathrm{P}<0.01$ vs. control. BBR, berberine; hERG1, human ether-a-go-go-related potassium channel $1 ; \mathrm{IC}_{50}$, half-maximal inhibitory concentration; sh, short hairpin RNA; OD, optical density.

of SKOV3 cells were detected in vitro using a CCK8 assay (Fig. 4A). The results demonstrated that knockdown of hERG1 in SKOV3 cells significantly reduced the cell proliferation activity compared with the control cells. BBR $(10 \mu \mathrm{M})$ was considered as a positive control group. As expected, knockdown of hERG1 exhibited similar cytotoxic effects as BBR treatment. These results suggest that hERG1 may serve a role in cell proliferation.

Furthermore, to determine whether hERG1 is involved in the process of cell migration and invasion, which represent the tumor migration and invasive abilities, Transwell assays were performed following the transfection of SKOV3 cells with sh-hERG1 or scramble control. As presented in Fig. 4B-E, knockdown of hERG1 significantly reduced the migration and invasion abilities of SKOV 3 cells. BBR $(10 \mu \mathrm{M})$ was used as a positive control. The results of the present study indicate that
hERG1 may be involved in the proliferation, migration and invasion processes of SKOV3 cells, and that BBR may be a potential therapeutic drug in the treatment of ovarian cancer.

Knockdown of hERGl inhibits ovarian tumor growth in vivo. To assess whether hERG1 is involved in ovarian cancer growth in vivo, nude mice were inoculated with SKOV3 cells, which were previously transfected with sh-hERG1 or shRNA-control plasmids. Following the outgrowth of palpable tumors, nude mice were randomly divided into four groups $(\mathrm{n}=3$ for each group) and fed via oral gavage with saline or BBR $(20 \mathrm{mg} / \mathrm{kg})$ twice per week. As presented in Fig. 5, the size and weight of ovarian cancer mass significantly decreased following the administration of BBR by oral gavage compared with the control group. Similarly, knockdown of hERG1 also significantly decreased tumor growth of xenografts compared with 

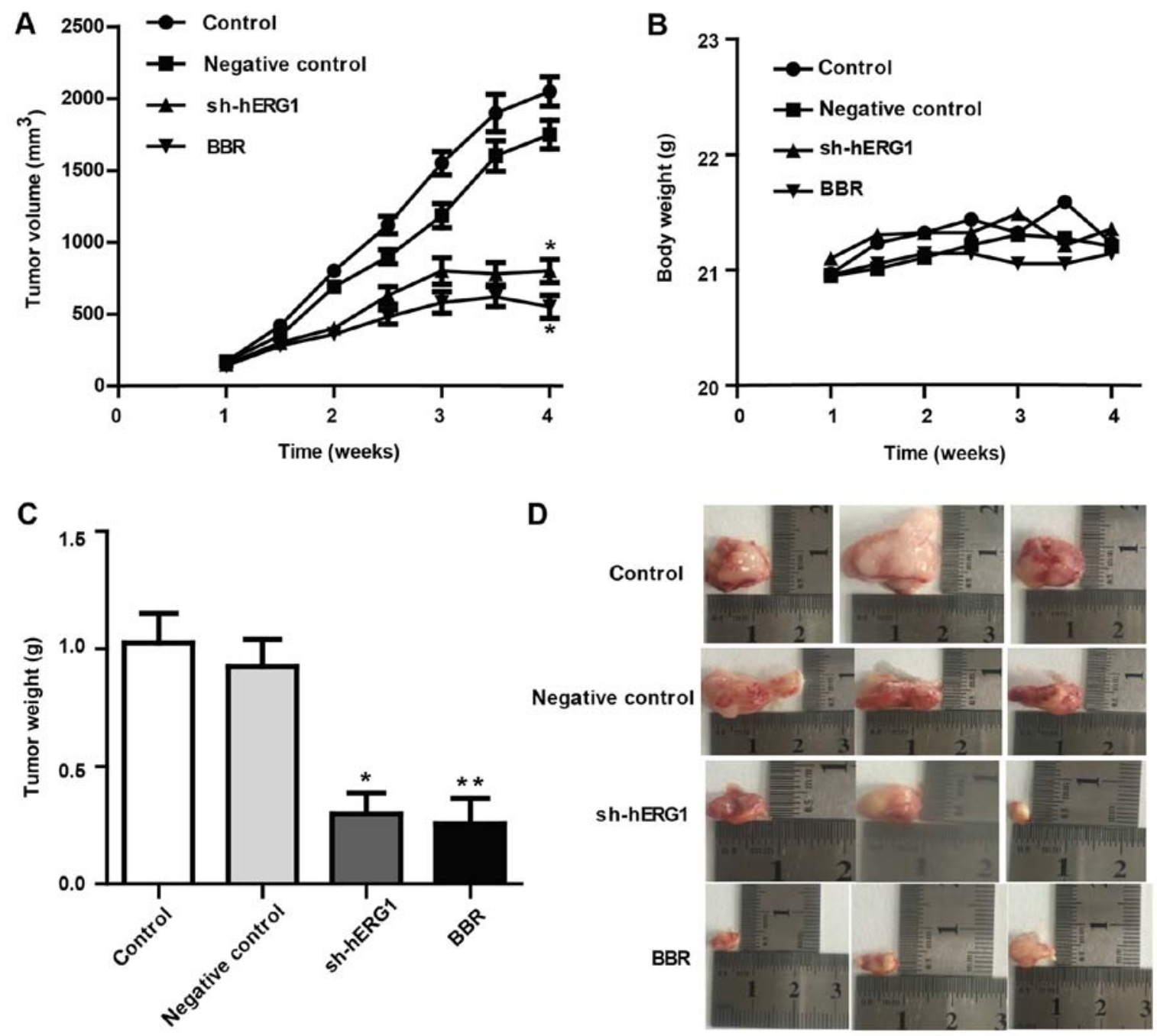

Figure 5. Knockdown of hERG1 inhibits ovarian tumor growth in vivo. (A) When tumors reached $100 \mathrm{~mm}^{3}$ in $\sim 1$ week, BBR treatment was initiated. Mice in the control group were injected with saline. (B) Body weight of mice with xenografts. No notable difference was detected in the body weight of mice among the four groups. (C) Weight of tumor samples from nude mice. (D) Macroscopic appearance of the tumors at 4 weeks after drug administration. $n=3$. "P<0.05, ${ }^{* * *} \mathrm{P}<0.01$ vs. control. BBR, berberine; hERG1, human ether-a-go-go-related potassium channel 1; sh, short hairpin RNA.

the control group. During the experiments, no notable weight loss was observed in mice of the different groups. These findings indicate that hERG1 may be involved in the pathogenesis of ovarian cancer and may be considered as a potential prognostic indicator in the treatment of ovarian cancer.

\section{Discussion}

Great efforts have been made in the treatment of ovarian cancer clinically; however, the prognosis of ovarian cancer remains poor due to drug resistance and tumor recurrence. In addition, tumor markers with appropriate specificity and sensitivity for the diagnosis and treatment of ovarian cancer remain to be identified $(31,32)$. Therefore, it is urgent to determine novel molecular markers to improve early diagnosis and effective therapy of ovarian cancer.

Over the past decades, BBR has drawn extensive attention due to its antitumorigenic effects in various types of human cancer cells and animal models $(33,34)$. Treatment with BBR has been reported to act on numerous targets and signaling pathways underlying pathophysiological process, including proliferation, apoptosis, angiogenesis, migration and invasion in a variety of cancer cells (35-37). In our previous study, BBR was observed to exert a strong inhibitory effect on hERG potassium channels $(22,38,39)$, which are often aberrantly expressed in carcinoma. Therefore, the present study proposed that BBR may inhibit ovarian cancer by targeting hERG1.

In the present study, it was demonstrated that the potassium ion channel protein, hERG1, serves a pivotal role in the pathophysiological process of SKOV3 ovarian cancer cells and may be inhibited by BBR in vitro and in vivo. The results of the present study suggest that BBR exerts a strong cytotoxic effect against ovarian cancer cells. This was demonstrated by the time- and dose-dependent inhibition of the proliferation of human ovarian cancer SKOV3 cells. A similar cytotoxic effect was achieved by knockdown of hERG1, which strongly suggests that hERG1 is involved in the ovarian cancer cell proliferation process. Additionally, the migration and invasion abilities of ovarian cancer SKOV3 cells were investigated. The results of the present study revealed that knockdown of hERG1 markedly reduced the 
migration and invasion abilities of ovarian cancer SKOV3 cells, which further suggests that hERG1 is an important regulator in the ovarian cancer phenotype. The results of the in vivo experimental results similarly supported the hypothesis of the present study, in which hERG1 was involved in the process of tumor growth and BBR could be a potential drug for the treatment of ovarian cancer.

During past decades, a number of studies have demonstrated the association between the activity of ion channels and the progression of different types of cancer, and considerable achievements have been made in understanding the role of ion channels in cancer $(7,40,41)$. hERG1 has been reported to exhibit oncogenic properties, is often aberrantly expressed in cancer and has essential roles in numerous crucial cellular events $(15,16)$. To the best of our knowledge, the present study revealed for the first time, that hERG1, as an important part of the potassium channel, may be the pivotal molecule to sense stimuli, transmit signals and eventually cause a series of signal pathway alterations within the cell.

In conclusion, hERG1 was demonstrated to be associated with the pathophysiological process of ovarian cancer SKOV3 cells, and the extract of a natural Chinese herbal medicine, BBR, may be of potential use as an anticancer agent for patients with ovarian cancer. The anticancer effects of BBR may be mediated by targeting the potassium hERG1 channel and eventually inducing a series of pathophysiological alterations in ovarian cancer cells. However, further studies are required to evaluate how BBR regulates the expression of hERG1 and the mechanism underlying the hERG1-mediated phenotypic alterations in ovarian cancer.

\section{Acknowledgements}

Not applicable.

\section{Funding}

This study was supported by the Haiyan Foundation from Harbin Medical University Cancer Hospital (grant no. JJQN2017-12) and the Harbin Medical University Scientific Research Innovation Fund (grant no. 2017LCZX97).

\section{Availability of data and materials}

The datasets used and/or analyzed during the current study are available from the corresponding author on reasonable request.

\section{Authors' contributions}

DZ was responsible for the design of the study and writing of the article. KZ was a major contributor in data analysis and was responsible for some experimental operations. XF performed the western blotting experiments. JZ performed the cell culture, transfection and proliferation assays. XL performed RT-qPCR, Transwell assays and the in vivo tumor xenograft study. DY was responsible for the immunohistochemical assays, and the revision of the article. MD was responsible for the design of the study and revision of the article. All authors read and approved the final manuscript.

\section{Ethics approval and consent to participate}

The present study has been approved by the Ethical Committee of the Harbin Medical University Cancer Hospital (Harbin, China) and written informed consent was obtained from all recruited patients.

\section{Patient consent for publication}

Not applicable.

\section{Competing interests}

The authors declare that they have no competing interests.

\section{References}

1. Wright JD, Chen L, Hou JY, Burke WM, Tergas AI, Ananth CV, Neugut AI and Hershman DL: Association of hospital volume and quality of care with survival for ovarian cancer. Obstet Gynecol 130: 545-553, 2017.

2. Lee YK, Chung HH, Kim JW, Song YS and Park NH: Expression of phosphorylated Akt and hTERT is associated with prognosis of epithelial ovarian carcinoma. Int J Clin Exp Pathol 8: 14971-14976, 2015.

3. Stefanou DT, Bamias A, Episkopou H, Kyrtopoulos SA, Likka M, Kalampokas T, Photiou S, Gavalas N, Sfikakis PP, Dimopoulos MA and Souliotis VL: Aberrant DNA damage response pathways may predict the outcome of platinum chemotherapy in ovarian cancer. PLoS One 10: e0117654, 2015.

4. Bandera EV, Lee VS, Qin B, Rodriguez-Rodriguez L, Powell CB and Kushi LH: Impact of body mass index on ovarian cancer survival varies by stage. Br J Cancer 117: 282-289, 2017.

5. Littleton JT and Ganetzky B: Ion channels and synaptic organization: Analysis of the Drosophila genome. Neuron 26: 35-43, 2000.

6. Curran ME: Potassium ion channels and human disease: Phenotypes to drug targets? Curr Opin Biotechnol 9: 565-572, 1998.

7. Ji CD, Wang YX, Xiang DF, Liu Q, Zhou ZH, Qian F, Yang L, Ren Y, Cui W, Xu SL, et al: Kir2.1 interaction with Stk38 promotes invasion and metastasis of human gastric cancer by enhancing MEKK2-MEK1/2-ERK1/2 signaling. Cancer Res 78: 3041-3053, 2018.

8. Cheng YY, Wright CM, Kirschner MB, Williams M, Sarun KH, Sytnyk V, Leshchynska I, Edelman JJ, Vallely MP, McCaughan BC, et al: KCa1.1, a calcium-activated potassium channel subunit alpha 1 , is targeted by miR-17-5p and modulates cell migration in malignant pleural mesothelioma. Mol Cancer 15: 44, 2016

9. Lastraioli E, Lottini T, Bencini L, Bernini M and Arcangeli A: hERG1 potassium channels: Novel biomarkers in human solid cancers. Biomed Res Int 2015: 896432, 2015.

10. Patanè S: HERG-targeted therapy in both cancer and cardiovascular system with cardiovascular drugs. Int J Cardiol 176: 1082-1085, 2014.

11. Leanza L, Biasutto L, Managò A, Gulbins E, Zoratti M and Szabò I: Intracellular ion channels and cancer. Front Physiol 4: 227, 2013

12. García-Quiroz J, García-Becerra R, Santos-Martínez N, Barrera D, Ordaz-Rosado D, Avila E, Halhali A, Villanueva O, Ibarra-Sánchez MJ, Esparza-López J, et al: In vivo dual targeting of the oncogenic Ether-à-go-go-1 potassium channel by calcitriol and astemizole results in enhanced antineoplastic effects in breast tumors. BMC Cancer 14: 745, 2014.

13. D'Amico M, Gasparoli L and Arcangeli A: Potassium channels: Novel emerging biomarkers and targets for therapy in cancer. Recent Pat Anticancer Drug Discov 8: 53-65, 2013.

14. Balijepalli SY, Lim E, Concannon SP, Chew CL, Holzem KE, Tester DJ, Ackerman MJ, Delisle BP, Balijepalli RC and January CT: Mechanism of loss of Kv11.1 K+ current in mutant T421M-Kv11.1-expressing rat ventricular myocytes: Interaction of trafficking and gating. Circulation 126: 2809-2818, 2012. 
15. Fortunato A: The role of hERG1 ion channels in epithelial-mesenchymal transition and the capacity of riluzole to reduce cisplatin resistance in colorectal cancer cells. Cell Oncol (Dordr) 40: 367-378, 2017

16. Becchetti A, Crescioli S, Zanieri F, Petroni G, Mercatelli R, Coppola S, Gasparoli L, D'Amico M, Pillozzi S, Crociani O, et al: The conformational state of hERG1 channels determines integrin association, downstream signaling, and cancer progression. Sci Signal 10: pii: eaaf3236, 2017.

17. Sundby E, Han J, Kaspersen SJ and Hoff BH: In vitro baselining of new pyrrolopyrimidine EGFR-TK inhibitors with Erlotinib. Eur J Pharm Sci 80: 56-65, 2015.

18. Fraley ME, Garbaccio RM, Arrington KL, Hoffman WF, Tasber ES, Coleman PJ, Buser CA, Walsh ES, Hamilton K, Fernandes C, et al: Kinesin spindle protein (KSP) inhibitors. Part 2: The design, synthesis, and characterization of 2,4-diaryl-2,5-dihydropyrrole inhibitors of the mitotic kinesin KSP. Bioorg Med Chem Lett 16: 1775-1779, 2006.

19. Gao J, Wang G, Wu J, Zuo Y, Zhang J and Chen J: Arsenic trioxide inhibits Skp2 expression to increase chemosensitivity to gemcitabine in pancreatic cancer cells. Am J Transl Res 11: 991-997, 2019.

20. Qu X, Wang F, Zhang Y, Du Z, Ren J, Liu Z and Zhang L: Biocompatible heterogeneous MOF-Cu catalyst used for in vivo drug synthesis at targeted subcellular organelles. Angew Chem Int Ed Engl: 19 Mar 2019 (Epub ahead of print) doi org/10.1002/anie.201901760.

21. Park HH, Choi SW, Lee GJ, Kim YD, Noh HJ, Oh SJ, Yoo I, Ha YJ, Koo GB, Hong SS, et al: A formulated red ginseng extract inhibits autophagic flux and sensitizes to doxorubicin-induced cell death. J Ginseng Res 43: 86-94, 2019

22. Zhi D, Feng PF, Sun JL, Guo F, Zhang R, Zhao X and Li BX: The enhancement of cardiac toxicity by concomitant administration of Berberine and macrolides. Eur J Pharm Sci 76: 149-155, 2015

23. Ortiz LM, Lombardi P, Tillhon M and Scovassi AI: Berberine, an epiphany against cancer. Molecules 19: 12349-12367, 2014.

24. Ayati SH, Fazeli B, Momtazi-Borojeni AA, Cicero AFG, Pirro M and Sahebkar A: Regulatory effects of berberine on microRNome in cancer and other conditions. Crit Rev Oncol Hematol 116: 147-158, 2017.

25. Wang J, Yang S, Cai X, Dong J, Chen Z, Wang R, Zhang S, Cao H, Lu D, Jin T, et al: Berberine inhibits EGFR signaling and enhances the antitumor effects of EGFR inhibitors in gastric cancer. Oncotarget 7: 76076-76086, 2016.

26. Wang $\mathrm{H}$, Li K, Ma L, Wu S, Hu J, Yan H, Jiang J and Li Y: Berberine inhibits enterovirus 71 replication by downregulating the MEK/ERK signaling pathway and autophagy. Virol J 14: 2, 2017.

27. Puthdee N, Seubwai W, Vaeteewoottacharn K, Boonmars T Cha'on U, Phoomak C and Wongkham S: Berberine induces cell cycle arrest in cholangiocarcinoma cell lines via inhibition of NF- $\kappa$ B and STAT3 pathways. Biol Pharm Bull 40: 751-757, 2017.

28. Hsu WH, Hsieh YS, Kuo HC, Teng CY, Huang HI, Wang CJ, Yang SF, Liou YS and Kuo WH: Berberine induces apoptosis in SW620 human colonic carcinoma cells through generation of reactive oxygen species and activation of JNK/p38 MAPK and FasL. Arch Toxicol 81: 719-728, 2007.
29. Xing Y, Ding T, Wang Z, Wang L, Guan H, Tang J, Mo D and Zhang J: Temporally-controlled photothermal/photodynamic and combined therapy for overcoming multidrug resistance of cancer by polydopamine nanoclustered micelles. ACS Appl Mater Interfaces: 2 Apr, 2019 (Epub ahead of print). doi: $10.1021 /$ acsami.9b00472

30. Livak KJ and Schmittgen TD: Analysis of relative gene expression data using real-time quantitative PCR and the 2(-Delta Delta C(T)) method. Methods 25: 402-408, 2001.

31. Capriglione S, Luvero D, Plotti F, Terranova C, Montera R, Scaletta G, Schirò T, Rossini G, Benedetti Panici P and Angioli R: Ovarian cancer recurrence and early detection: May HE4 play a key role in this open challenge? A systematic review of literature. Med Oncol 34: 164, 2017.

32. Yi H, Zheng X, Song J, Shen R, Su Y and Lin D: Exosomes mediated pentose phosphate pathway in ovarian cancer metastasis: A proteomics analysis. Int J Clin Exp Pathol 8: 15719-15728, 2015.

33. Zheng F, Wu J, Tang Q, Xiao Q, Wu W and Hann SS: The enhancement of combination of berberine and metformin in inhibition of DNMT1 gene expression through interplay of SP1 and PDPK1. J Cell Mol Med 22: 600-612, 2018.

34. Wang X, Wang N, Li H, Liu M, Cao F, Yu X, Zhang J, Tan Y, Xiang L and Feng Y: Up-regulation of PAI-1 and down-regulation of uPA are involved in suppression of invasiveness and motility of hepatocellular carcinoma cells by a natural compound berberine. Int J Mol Sci 17: 577, 2016.

35. Li D, Zhang Y, Liu K, Zhao Y, Xu B, Xu L, Tan L, Tian Y, Li C, Zhang W, et al: Berberine inhibits colitis-associated tumorigenesis via suppressing inflammatory responses and the consequent EGFR signaling-involved tumor cell growth. Lab Invest 97: 1343-1353, 2017.

36. Chu SC, Yu CC, Hsu LS, Chen KS, Su MY and Chen PN: Berberine reverses epithelial-to-mesenchymal transition and inhibits metastasis and tumor-induced angiogenesis in human cervical cancer cells. Mol Pharmacol 86: 609-623, 2014.

37. Liu X, Ji Q, Ye N, Sui H, Zhou L, Zhu H, Fan Z, Cai J and Li Q: Berberine inhibits invasion and metastasis of colorectal cancer cells via COX-2/PGE2 mediated JAK2/STAT3 signaling pathway. PLoS One 10: e0123478, 2015.

38. Yan M, Zhang K, Shi Y, Feng L, Lv L and Li B: Mechanism and pharmacological rescue of berberine-induced hERG channel deficiency. Drug Des Devel Ther 9: 5737-5747, 2015.

39. Zhang K, Zhi D, Huang T, Gong Y, Yan M, Liu C, Wei T, Dong Z, Li B and Yang B: Berberine induces hERG channel deficiency through trafficking inhibition. Cell Physiol Biochem 34: 691-702, 2014.

40. Xia J, Wang H, Li S, Wu Q, Sun L, Huang H and Zeng M: Ion channels or aquaporins as novel molecular targets in gastric cancer. Mol Cancer 16: 54, 2017.

41. Arcangeli A and Becchetti A: Novel perspectives in cancer therapy: Targeting ion channels. Drug Resist Updat 21-22: 11-19, 2015.

This work is licensed under a Creative Commons Attribution-NonCommercial-NoDerivatives 4.0 International (CC BY-NC-ND 4.0) License. 